\title{
Synthesis and SAR analysis of lipovelutibols B and D and their lipid analogues
}

Alan J. Cameron, ${ }^{a, b, c}$ Emma K. Davison, , ${ }^{a, b, c}$ Chalice An, ${ }^{a, b}$ Louise A. Stubbing, ${ }^{a, c} P$. Rod Dunbar, ${ }^{b, c}$ Paul W. R. Harris, ${ }^{a, b, c}$ and Margaret A. Brimble ${ }^{\star a, b, c}$

${ }^{a}$ School of Chemical Sciences, University of Auckland, 23 Symonds St., Auckland, 1010, New Zealand

\section{Email: m.brimble@auckland.ac.nz}

${ }^{b}$ School of Biological Sciences, University of Auckland, 3 Symonds St., Auckland, 1010, New

\section{Zealand}

'The Maurice Wilkins Centre for Molecular Biodiscovery, The University of Auckland, Private Bag 92019, Auckland, 1142, New Zealand

\section{Table of Contents}

\section{NMR Data Tables}

Table $\mathrm{S} 1-{ }^{1} \mathrm{H}$ and ${ }^{13} \mathrm{C}$ NMR comparison of natural lipovelutibol $\mathrm{D}(\mathbf{4})$ with synthetic lipovelutibol $D(4)$ in DMSO-d 6

Table $\mathrm{S} 2-{ }^{1} \mathrm{H}$ and ${ }^{13} \mathrm{C}$ NMR comparison of natural lipovelutibol B (2) with synthetic lipovelutibol $\mathrm{B}(2)$ in $\mathrm{CD}_{3} \mathrm{OH}$

\section{Spectra and Chromatograms of Peptides}

Analytical RP-HPLC chromatograms and HRMS spectra of 2, 2a-c, 4, and 4a-c

${ }^{1} \mathrm{H}$ and ${ }^{13} \mathrm{C}$ NMR spectra of lipovelutibol $\mathrm{D}(\mathbf{4})$

${ }^{1} \mathrm{H}$ and ${ }^{13} \mathrm{C}$ NMR spectra of lipovelutibol $\mathrm{B}(2)$

\section{Biological Assays}

Table S3 - MIC assay results for fungal and bacterial pathogens 
Table S1. ${ }^{1} \mathrm{H}$ and ${ }^{13} \mathrm{C}$ NMR comparison of natural lipovelutibol $\mathrm{D}(4)^{1}$ with synthetic lipovelutibol D (4) in DMSO-d 6 .

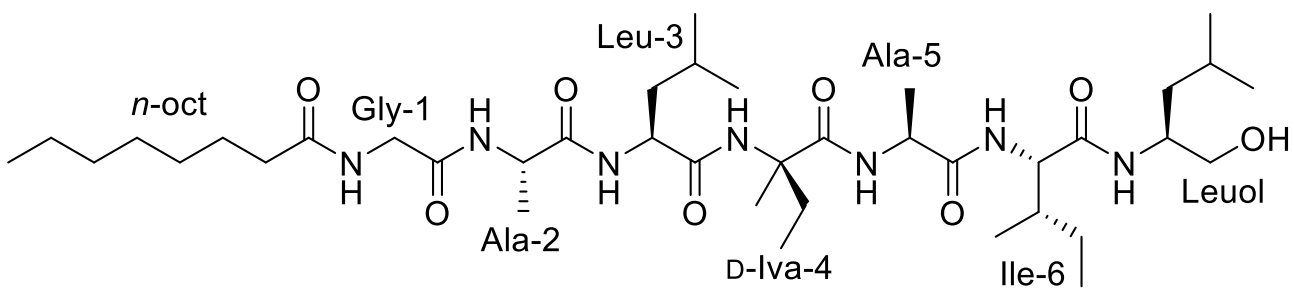

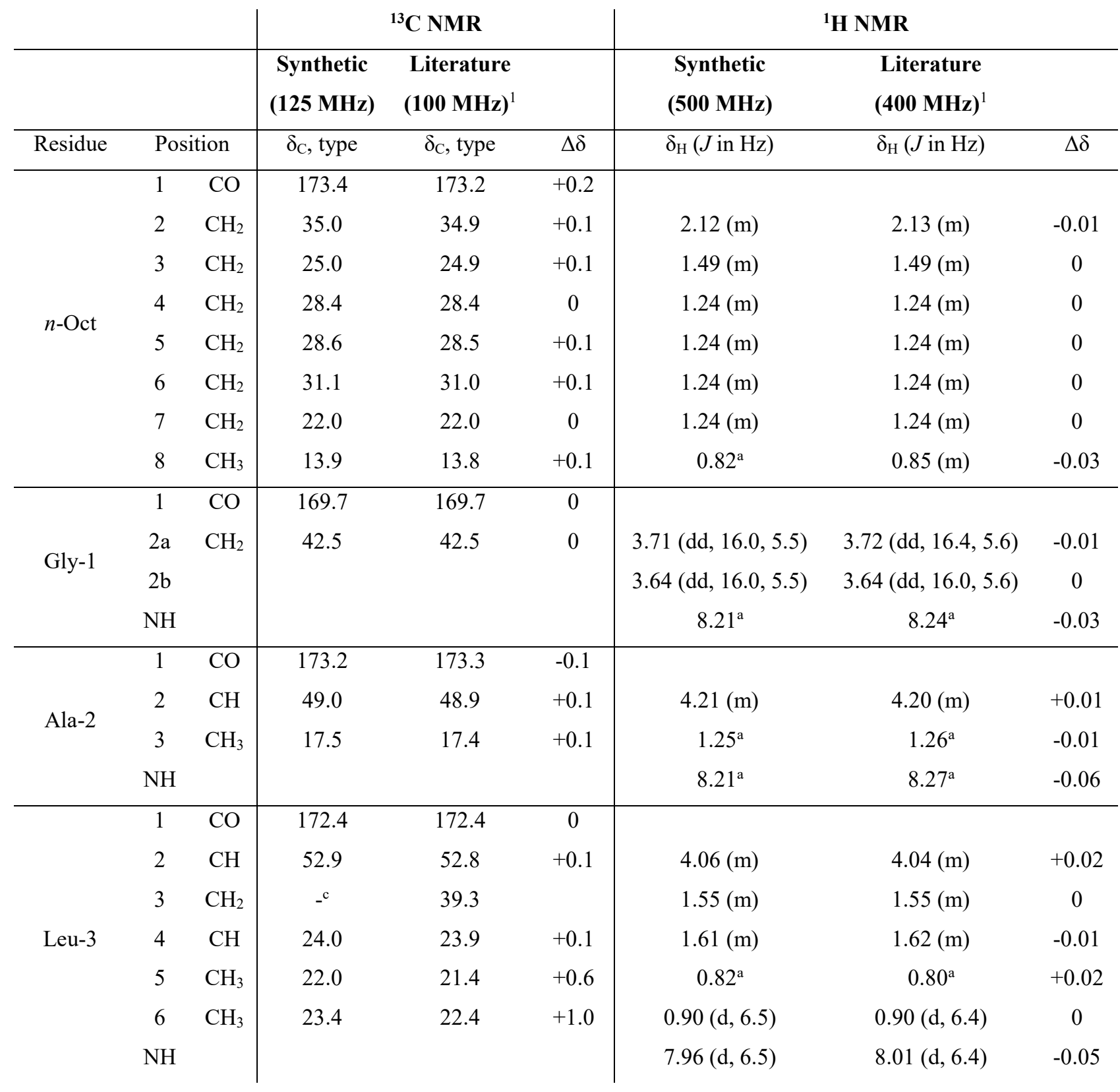


Table S1 (continued). ${ }^{1} \mathrm{H}$ and ${ }^{13} \mathrm{C}$ NMR comparison of natural lipovelutibol $\mathrm{D}(4)^{1}$ with synthetic lipovelutibol D (4) in DMSO-d 6 .

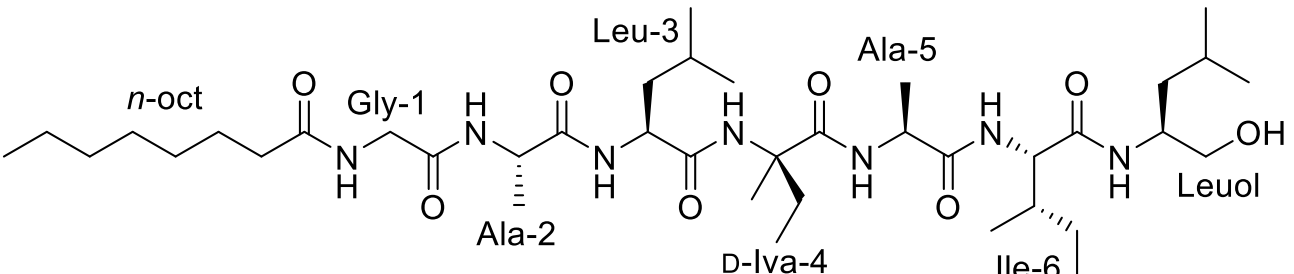

\begin{tabular}{|c|c|c|c|c|c|c|c|c|}
\hline Residue & & tion & $\delta_{\mathrm{C}}$, type & $\delta_{\mathrm{C}}$, type & $\overline{\Delta \delta}$ & $\delta_{\mathrm{H}}(J$ in $\mathrm{Hz})$ & $\delta_{\mathrm{H}}(J$ in $\mathrm{Hz})$ & $\overline{\Delta \delta}$ \\
\hline \multirow{7}{*}{ D-Iva-4 } & 1 & $\mathrm{CO}$ & 174.2 & 174.0 & +0.2 & & & \\
\hline & 2 & $\mathrm{C}$ & 59.9 & 58.8 & +1.1 & & & \\
\hline & 3 & $\mathrm{CH}_{3}$ & 21.7 & 21.6 & +0.1 & $1.30(\mathrm{~s})$ & $1.30(\mathrm{~s})$ & 0 \\
\hline & $4 a$ & $\mathrm{CH}_{2}$ & 27.4 & 27.3 & +0.1 & $1.97(\mathrm{~m})$ & $1.97(\mathrm{~m})$ & 0 \\
\hline & $4 b$ & & & & & $1.77(\mathrm{~m})$ & $1.77(\mathrm{~m})$ & 0 \\
\hline & 5 & $\mathrm{CH}_{3}$ & 7.4 & 7.3 & +0.1 & $0.69(\mathrm{t}, 7.5)$ & $0.69(\mathrm{t}, 7.6)$ & 0 \\
\hline & $\mathrm{NH}$ & & & & & $7.72(\mathrm{~s})$ & $7.76(\mathrm{~s})$ & -0.04 \\
\hline \multirow{4}{*}{ Ala-5 } & 1 & $\mathrm{CO}$ & 172.2 & 172.1 & +0.1 & & & \\
\hline & 2 & $\mathrm{CH}$ & 49.6 & 49.5 & +0.1 & $4.06(\mathrm{~m})$ & $4.04(\mathrm{~m})$ & +0.02 \\
\hline & 3 & $\mathrm{CH}_{3}$ & 17.4 & 17.3 & +0.1 & $1.25^{\mathrm{a}}$ & $1.26^{\mathrm{a}}$ & -0.01 \\
\hline & $\mathrm{NH}$ & & & & & $7.40(\mathrm{~m})$ & $7.41(\mathrm{~m})$ & -0.01 \\
\hline \multirow{8}{*}{ Ile-6 } & 1 & $\mathrm{CO}$ & 170.3 & 170.2 & +0.1 & & & \\
\hline & 2 & $\mathrm{CH}$ & 57.6 & 57.5 & +0.1 & $4.06(\mathrm{~m})$ & $4.04(\mathrm{~m})$ & +0.02 \\
\hline & 3 & $\mathrm{CH}$ & 36.3 & 36.2 & +0.1 & $1.77(\mathrm{~m})$ & $1.77(\mathrm{~m})$ & 0 \\
\hline & 4 & $\mathrm{CH}_{3}$ & 15.3 & 15.3 & 0 & $0.82^{\mathrm{a}}$ & $0.83^{\mathrm{a}}$ & -0.01 \\
\hline & $5 \mathrm{a}$ & $\mathrm{CH}_{2}$ & 24.4 & 24.3 & +0.1 & $1.14(\mathrm{~m})$ & $1.13(\mathrm{~m})$ & +0.01 \\
\hline & $5 b$ & & & & & $1.45(\mathrm{~m})$ & $1.43(\mathrm{~m})$ & +0.02 \\
\hline & 6 & $\mathrm{CH}_{3}$ & 11.2 & 11.2 & 0 & $0.82^{\mathrm{a}}$ & $0.80^{\mathrm{a}}$ & +0.02 \\
\hline & $\mathrm{NH}$ & & & & & $7.40(\mathrm{~m})$ & $7.41(\mathrm{~m})$ & -0.01 \\
\hline \multirow{9}{*}{ Leuol } & 1 & $\mathrm{CH}$ & 48.5 & 48.4 & +0.1 & $3.80(\mathrm{~m})$ & $3.82(\mathrm{~m})$ & -0.02 \\
\hline & $2 \mathrm{a}$ & $\mathrm{CH}_{2}$ & 64.0 & 63.9 & +0.1 & $3.28(\mathrm{~m})$ & $3.28(\mathrm{~m})$ & 0 \\
\hline & $2 b$ & & & & & $3.13(\mathrm{~m})$ & $3.14(\mathrm{~m})$ & -0.01 \\
\hline & $\mathrm{OH}$ & & & & & $-{ }^{b}$ & $4.52(t, 5.6)$ & \\
\hline & 3 & $\mathrm{CH}_{2}$ & $--^{c}$ & 39.7 & & $1.33(\mathrm{~m})$ & $1.34(\mathrm{~m})$ & -0.01 \\
\hline & 4 & $\mathrm{CH}$ & 24.2 & 24.1 & +0.1 & $1.61(\mathrm{~m})$ & $1.63(\mathrm{~m})$ & -0.02 \\
\hline & 5 & $\mathrm{CH}_{3}$ & 21.4 & 21.4 & 0 & $0.82^{\mathrm{a}}$ & $0.80^{\mathrm{a}}$ & +0.02 \\
\hline & 6 & $\mathrm{CH}_{3}$ & 22.5 & 21.9 & +1.4 & $0.82^{\mathrm{a}}$ & $0.83^{\mathrm{a}}$ & -0.01 \\
\hline & $\mathrm{NH}$ & & & & & $7.09(\mathrm{~d}, 9.0)$ & $7.10(\mathrm{~d}, 9.2)$ & -0.01 \\
\hline \multicolumn{9}{|c|}{ a Unresolved } \\
\hline${ }^{b}$ Not & & & & & & & & \\
\hline
\end{tabular}


Table S2. ${ }^{1} \mathrm{H}$ and ${ }^{13} \mathrm{C}$ NMR comparison of natural lipovelutibol $\mathrm{B}(2)^{1}$ with synthetic lipovelutibol $\mathrm{B}(2)$ in $\mathrm{CD}_{3} \mathrm{OH}$.

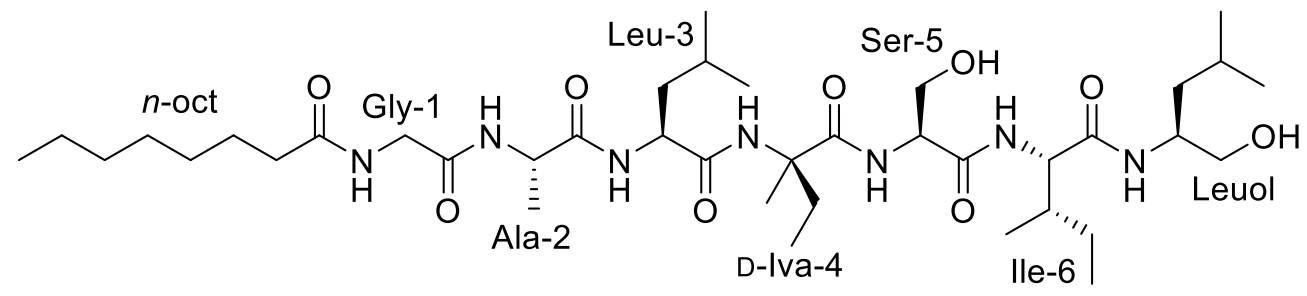

\begin{tabular}{|c|c|c|c|c|c|c|c|c|}
\hline & & & \multicolumn{3}{|c|}{${ }^{13} \mathrm{C}$ NMR } & \multicolumn{3}{|c|}{${ }^{1}$ H NMR } \\
\hline & & & $\begin{array}{l}\text { Synthetic } \\
\text { (100 MHz) }\end{array}$ & $\begin{array}{l}\text { Literature } \\
(125 \mathrm{MHz})^{1}\end{array}$ & & $\begin{array}{l}\text { Synthetic } \\
\text { (400 MHz) }\end{array}$ & $\begin{array}{l}\text { Literature } \\
(500 \mathrm{MHz})^{1}\end{array}$ & \\
\hline Residue & Pos & tion & $\delta_{\mathrm{C}}$, type & $\delta_{\mathrm{C}}$, type & $\Delta \delta$ & $\delta_{\mathrm{H}}(J$ in $\mathrm{Hz})$ & $\delta_{\mathrm{H}}(J$ in $\mathrm{Hz})$ & $\Delta \delta$ \\
\hline \multirow{8}{*}{$n$-Oct } & & $\mathrm{CO}$ & 177.2 & 177.3 & -0.1 & & & \\
\hline & 2 & $\mathrm{CH}_{2}$ & 36.6 & 36.7 & -0.1 & $2.30(\mathrm{~m})$ & $2.28(\mathrm{~m})$ & +0.02 \\
\hline & 3 & $\mathrm{CH}_{2}$ & 26.6 & 26.7 & -0.1 & $1.65(\mathrm{~m})$ & $1.63(\mathrm{~m})$ & +0.02 \\
\hline & 4 & $\mathrm{CH}_{2}$ & 30.1 & 30.4 & -0.3 & $1.35(\mathrm{~m})$ & $1.32(\mathrm{~m})$ & +0.03 \\
\hline & 5 & $\mathrm{CH}_{2}$ & 30.2 & 30.3 & -0.1 & $1.35(\mathrm{~m})$ & $1.32(\mathrm{~m})$ & +0.03 \\
\hline & 6 & $\mathrm{CH}_{2}$ & 32.8 & 32.9 & -0.1 & $1.35(\mathrm{~m})$ & $1.32(\mathrm{~m})$ & +0.03 \\
\hline & 7 & $\mathrm{CH}_{2}$ & 23.6 & 23.7 & -0.1 & $1.35(\mathrm{~m})$ & $1.32(\mathrm{~m})$ & +0.03 \\
\hline & 8 & $\mathrm{CH}_{3}$ & 14.3 & 14.4 & -0.1 & $0.95(\mathrm{~d}, 6.2)$ & $0.92(\mathrm{~m})$ & +0.03 \\
\hline \multirow{4}{*}{ Gly-1 } & 1 & $\mathrm{CO}$ & 172.9 & 173.1 & -0.2 & & & \\
\hline & $2 \mathrm{a}$ & $\mathrm{CH}_{2}$ & 44.4 & 44.6 & -0.2 & $3.88(\mathrm{~m})$ & $3.86(\mathrm{~m})$ & +0.02 \\
\hline & $2 \mathrm{~b}$ & & & & & $3.77(\mathrm{dd}, 16.2,5.2)$ & $3.75(\mathrm{dd}, 16.0,5.0)$ & +0.02 \\
\hline & $\mathrm{NH}$ & & & & & $8.38(t, 5.2)$ & $8.43(t, 5.0)$ & -0.05 \\
\hline \multirow{4}{*}{ Ala-2 } & & $\mathrm{CO}$ & 176.8 & 176.9 & -0.1 & & & \\
\hline & 2 & $\mathrm{CH}$ & 52.0 & 52.1 & -0.1 & $4.28(\mathrm{~m})$ & $4.24,(\mathrm{~m})$ & +0.04 \\
\hline & 3 & $\mathrm{CH}_{3}$ & 17.1 & 17.3 & -0.2 & $1.45^{\mathrm{a}}$ & $1.42^{\mathrm{a}}$ & +0.03 \\
\hline & $\mathrm{NH}$ & & & & & $8.51(\mathrm{~d}, 5.2)$ & $8.57(\mathrm{~d}, 2.5)$ & -0.06 \\
\hline \multirow{8}{*}{ Leu-3 } & 1 & $\mathrm{CO}$ & 175.2 & 175.4 & -0.2 & & & \\
\hline & 2 & $\mathrm{CH}$ & 55.6 & 55.5 & +0.1 & $4.13(\mathrm{~m})$ & $4.10(\mathrm{~m})$ & +0.03 \\
\hline & $3 a$ & $\mathrm{CH}_{2}$ & 40.7 & 40.9 & -0.2 & $1.81(\mathrm{~m})$ & $1.80(\mathrm{~m})$ & +0.01 \\
\hline & $3 b$ & & & & & $1.70(\mathrm{~m})$ & $1.70(\mathrm{~m})$ & 0 \\
\hline & 4 & $\mathrm{CH}$ & 25.5 & 25.7 & -0.2 & $1.70(\mathrm{~m})$ & $1.70(\mathrm{~m})$ & 0 \\
\hline & 5 & $\mathrm{CH}_{3}$ & 22.2 & 22.3 & -0.1 & $0.91(\mathrm{~m})$ & $0.89(\mathrm{~m})$ & +0.02 \\
\hline & 6 & $\mathrm{CH}_{3}$ & 22.8 & 23.0 & -0.2 & $1.01(\mathrm{~d}, 5.9)$ & $0.99(\mathrm{~d}, 6.0)$ & +0.02 \\
\hline & $\mathrm{NH}$ & $\mathrm{NH}$ & & & & $8.08(\mathrm{~d}, 5.6)$ & $8.11(\mathrm{~d}, 5.5)$ & -0.03 \\
\hline
\end{tabular}


Table S2 (continued). ${ }^{1} \mathrm{H}$ and ${ }^{13} \mathrm{C}$ NMR comparison of natural lipovelutibol B (2) ${ }^{1}$ with synthetic lipovelutibol $\mathrm{B}(2)$ in $\mathrm{CD}_{3} \mathrm{OH}$.

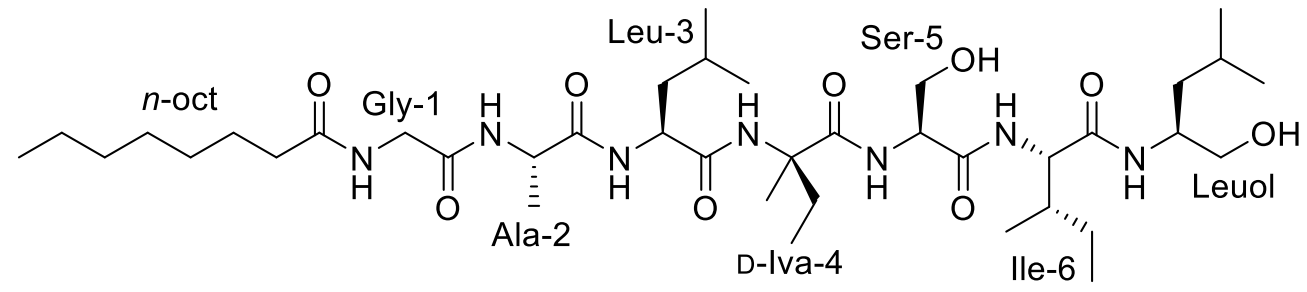

\begin{tabular}{|c|c|c|c|c|c|c|c|c|}
\hline Residue & \multicolumn{2}{|c|}{ Position } & $\delta_{\mathrm{C}}$, type & $\delta_{\mathrm{C}}$, type & $\Delta \delta$ & $\delta_{\mathrm{H}}(J$ in $\mathrm{Hz})$ & $\delta_{\mathrm{H}}(J$ in $\mathrm{Hz})$ & $\Delta \delta$ \\
\hline \multirow{7}{*}{ D-Iva-4 } & 1 & $\mathrm{CO}$ & 178.2 & 178.3 & -0.1 & & & \\
\hline & 2 & C & 60.8 & 60.9 & -0.1 & & & \\
\hline & 3 & $\mathrm{CH}_{3}$ & 22.8 & 23.0 & -0.2 & $1.41(\mathrm{~s})$ & $1.41(\mathrm{~s})$ & 0 \\
\hline & $4 a$ & $\mathrm{CH}_{2}$ & 27.9 & 28.1 & -0.2 & $2.25(\mathrm{~m})$ & $2.22,(\mathrm{~m})$ & +0.03 \\
\hline & $4 \mathrm{~b}$ & & & & & $1.81(\mathrm{~m})$ & $1.80(\mathrm{~m})$ & +0.01 \\
\hline & 5 & $\mathrm{CH}_{3}$ & 7.7 & 7.9 & -0.2 & $0.85(\mathrm{t}, 6.8)$ & $0.82(\mathrm{t}, 7.5)$ & +0.03 \\
\hline & $\mathrm{NH}$ & & & & & $7.80(\mathrm{~s})$ & $7.82(\mathrm{~s})$ & -0.02 \\
\hline \multirow{4}{*}{ Ser-5 } & 1 & $\mathrm{CO}$ & 173.1 & 173.2 & -0.1 & & & \\
\hline & 2 & $\mathrm{CH}$ & 59.4 & 59.5 & -0.1 & $4.22(\mathrm{~m})$ & $4.18(\mathrm{~m})$ & +0.04 \\
\hline & 3 & $\mathrm{CH}_{2}$ & 62.6 & 62.8 & -0.2 & $3.95(\mathrm{~m})$ & $3.92(\mathrm{~m})$ & +0.03 \\
\hline & $\mathrm{NH}$ & $\mathrm{NH}$ & & & & $7.58(\mathrm{~d}, 2.0)$ & $7.59(\mathrm{~d}, 5.5)$ & -0.01 \\
\hline \multirow{8}{*}{ Ile- 6} & 1 & $\mathrm{CO}$ & 173.6 & 173.7 & -0.1 & & & \\
\hline & 2 & $\mathrm{CH}$ & 60.7 & 60.8 & -0.1 & $4.28(\mathrm{~m})$ & $4.24(\mathrm{~m})$ & +0.04 \\
\hline & 3 & $\mathrm{CH}$ & 37.6 & 37.7 & -0.1 & $2.03(\mathrm{~m})$ & $2.01(\mathrm{~m})$ & +0.02 \\
\hline & 4 & $\mathrm{CH}_{3}$ & 15.8 & 16.1 & -0.3 & $0.98(\mathrm{~d}, 6.8)$ & $0.95(\mathrm{~d}, 6.5)$ & +0.03 \\
\hline & $5 \mathrm{a}$ & $\mathrm{CH}_{2}$ & 26.1 & 26.3 & -0.2 & $1.35(\mathrm{~m})$ & $1.33(\mathrm{~m})$ & +0.02 \\
\hline & $5 b$ & & & & & $1.70(\mathrm{~m})$ & $1.70(\mathrm{~m})$ & 0 \\
\hline & 6 & $\mathrm{CH}_{3}$ & 11.8 & 11.9 & -0.1 & $0.90(\mathrm{~m})$ & $0.87(\mathrm{~m})$ & +0.03 \\
\hline & $\mathrm{NH}$ & & & & & $7.67(\mathrm{~d}, 8.8)$ & $7.67(\mathrm{~d}, 8.5)$ & 0 \\
\hline \multirow{8}{*}{ Leuol } & 1 & $\mathrm{CH}$ & 50.8 & 50.5 & +0.3 & $4.06(\mathrm{~m})$ & $4.03(\mathrm{~m})$ & +0.03 \\
\hline & 2 & $\mathrm{CH}_{2}$ & 66.0 & 66.1 & -0.1 & $3.48(\mathrm{~m})$ & $3.48(\mathrm{~m})$ & 0 \\
\hline & $3 a$ & $\mathrm{CH}_{2}$ & 40.7 & 40.9 & -0.2 & $1.48(\mathrm{~m})$ & $1.48(\mathrm{~m})$ & 0 \\
\hline & $3 b$ & & & & & $1.39(\mathrm{~m})$ & $1.37(\mathrm{~m})$ & +0.02 \\
\hline & 4 & $\mathrm{CH}$ & 25.8 & $27.0(26.0)^{\mathrm{b}}$ & -0.2 & $1.59(\mathrm{~m})$ & $1.57(\mathrm{~m})$ & +0.02 \\
\hline & 5 & $\mathrm{CH}_{3}$ & 23.9 & 24.1 & -0.2 & $0.92^{\mathrm{a}}$ & $0.90^{\mathrm{a}}$ & +0.02 \\
\hline & 6 & $\mathrm{CH}_{3}$ & 21.8 & 21.9 & -0.1 & $0.92^{\mathrm{a}}$ & $0.90^{\mathrm{a}}$ & +0.02 \\
\hline & $\mathrm{NH}$ & & & & & $7.18(\mathrm{~d}, 8.8)$ & $7.18(\mathrm{~d}, 9.0)$ & 0 \\
\hline
\end{tabular}

${ }^{a}$ Unresolved

${ }^{\mathrm{b}}$ Apparent error in literature table when analysing spectrum provided in supporting information by authors; correct value should be 26.0 


\section{RP-HPLC chromatograms and HRMS spectra of synthesised peptides}

a.

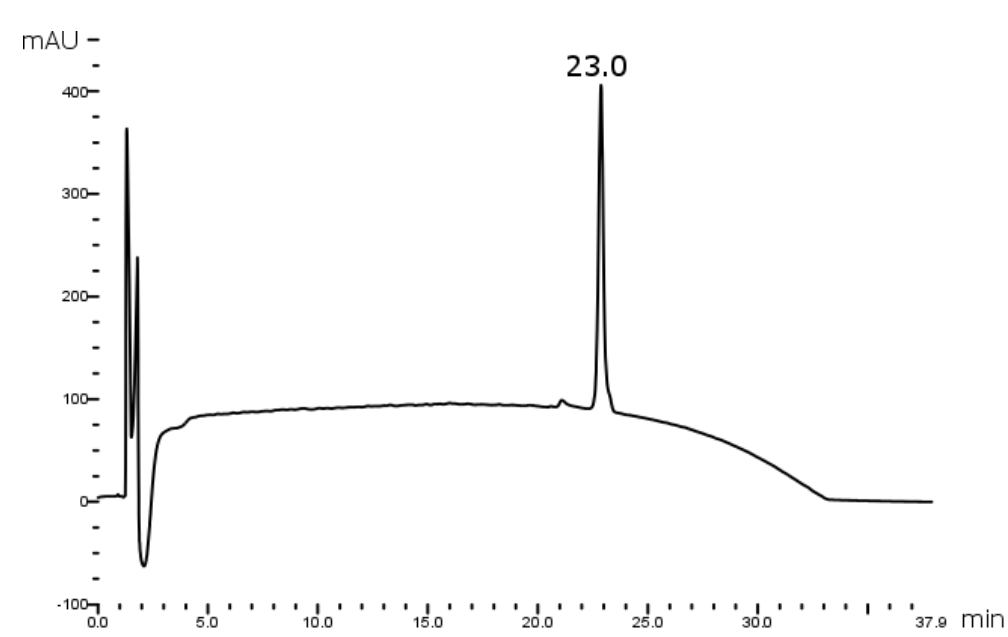

b.

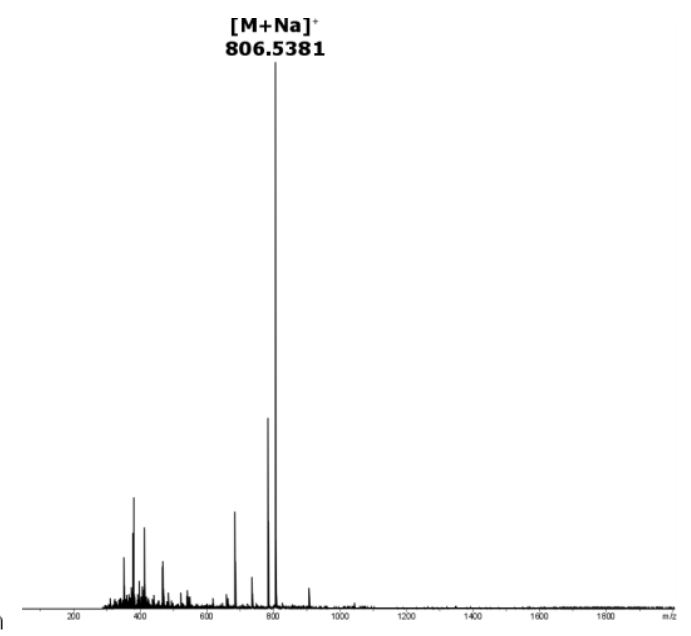

Figure S1. a. Analytical HPLC chromatogram of purified lipovelutibol B (2), 98\% purity (214 nm, peaks with $t_{R}<4$ min result from solvent spikes during injection); XTerra MS C18, $125 \AA$, $5 \mu \mathrm{m}, 4.6 \times 150 \mathrm{~mm}, 5-95 \% \mathrm{~B}$ at $3 \%$ B per

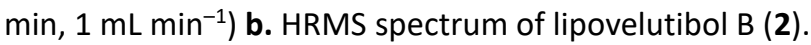

a.

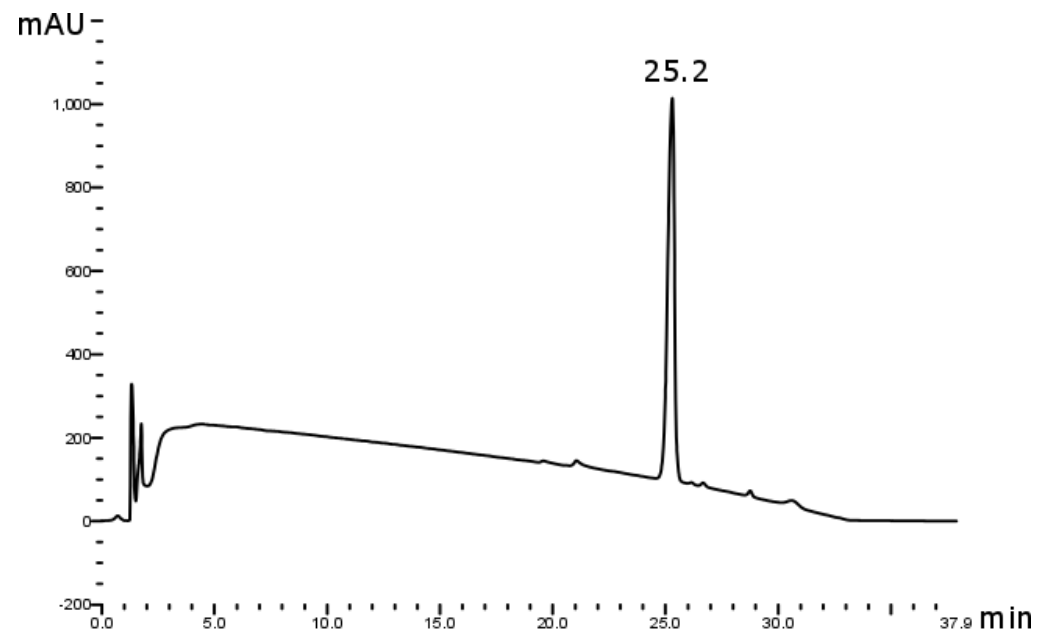

b.

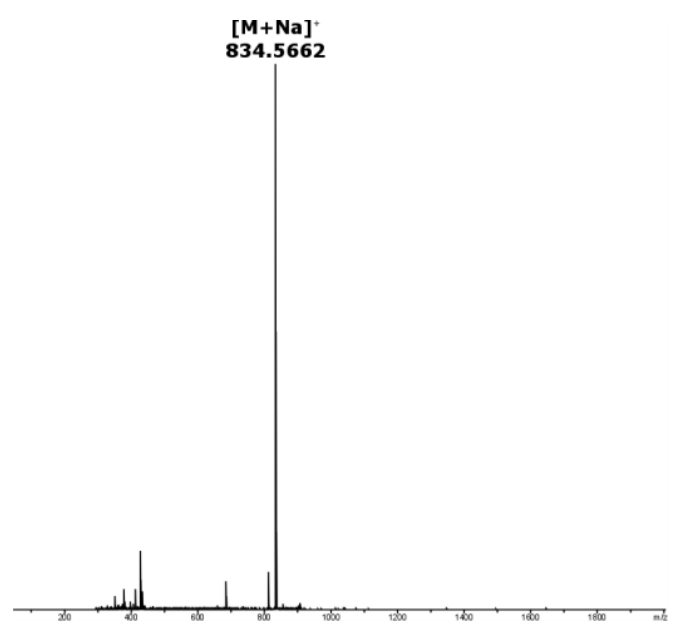

Figure S2. Analytical HPLC chromatogram of purified lipovelutibol B analogue $2 \mathrm{a},>99 \%$ purity (214 nm, peaks with $\mathrm{t}_{\mathrm{R}}<4$ min result from solvent spikes during injection); XTerra MS C18, $125 \AA$, $5 \mu \mathrm{m}, 4.6 \times 150 \mathrm{~mm}, 5-95 \% \mathrm{~B}$ at $3 \%$ B per $\min , 1 \mathrm{~mL} \mathrm{~min}^{-1}$ ) b. HRMS spectrum of lipovelutibol B analogue 2 a. 
a.

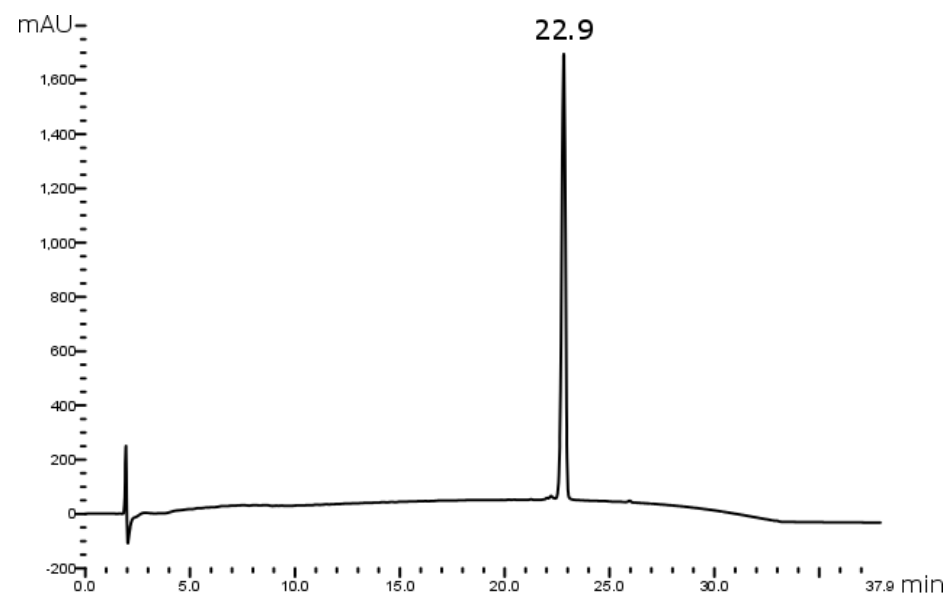

b.

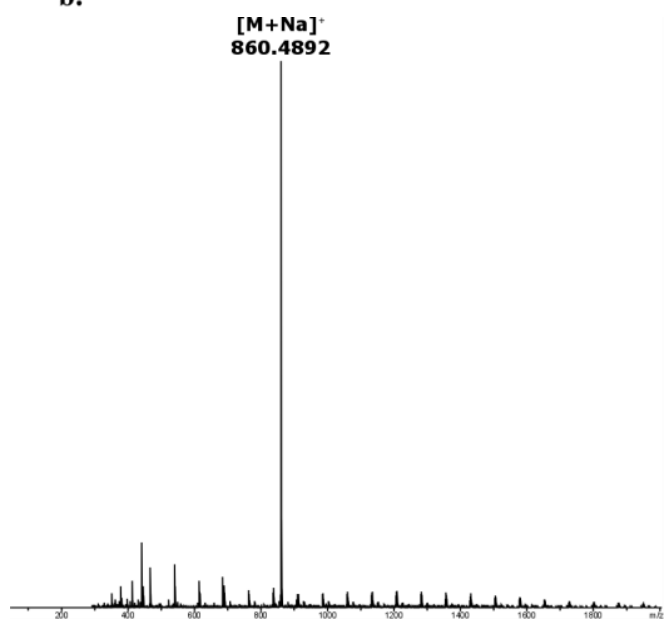

Figure S3. Analytical HPLC chromatogram of purified lipovelutibol B analogue $\mathbf{2 b}$, >99\% purity (214 nm, peaks with $\mathrm{t}_{\mathrm{R}}<4$ min result from solvent spikes during injection); XTerra MS C18, $125 \AA$, $5 \mu \mathrm{m}, 4.6 \times 150 \mathrm{~mm}, 5-95 \% \mathrm{~B}$ at $3 \% \mathrm{~B}$ per $\min , 1 \mathrm{~mL} \mathrm{~min}^{-1}$ ) b. HRMS spectrum of lipovelutibol $B$ analogue $\mathbf{2 b}$.

a.

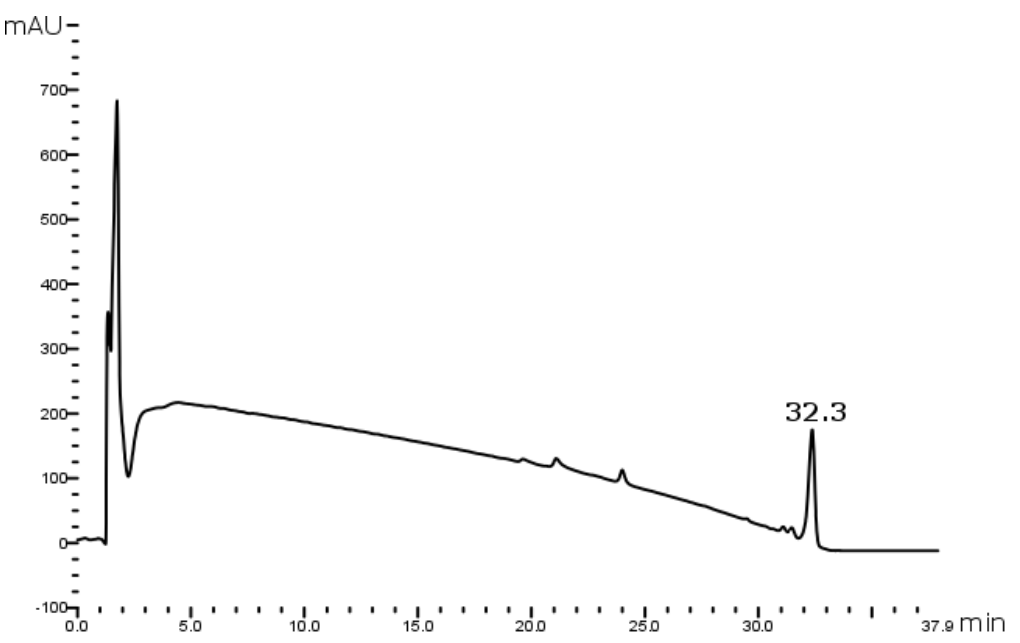

b.

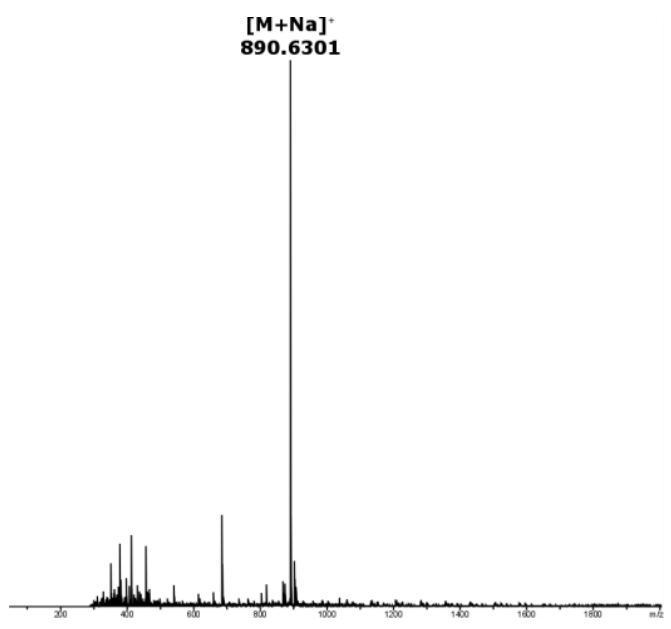

Figure S4. Analytical HPLC chromatogram of purified lipovelutibol B analogue 2c, 96\% purity (214 nm, peaks with $\mathrm{t}_{\mathrm{R}}<4$ min result from solvent spikes during injection); XTerra MS C18, $125 \AA$, $5 \mu \mathrm{m}, 4.6 \times 150 \mathrm{~mm}, 5-95 \%$ B at 3\%

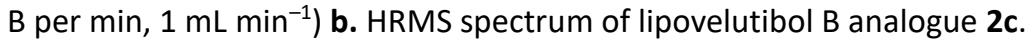


a.

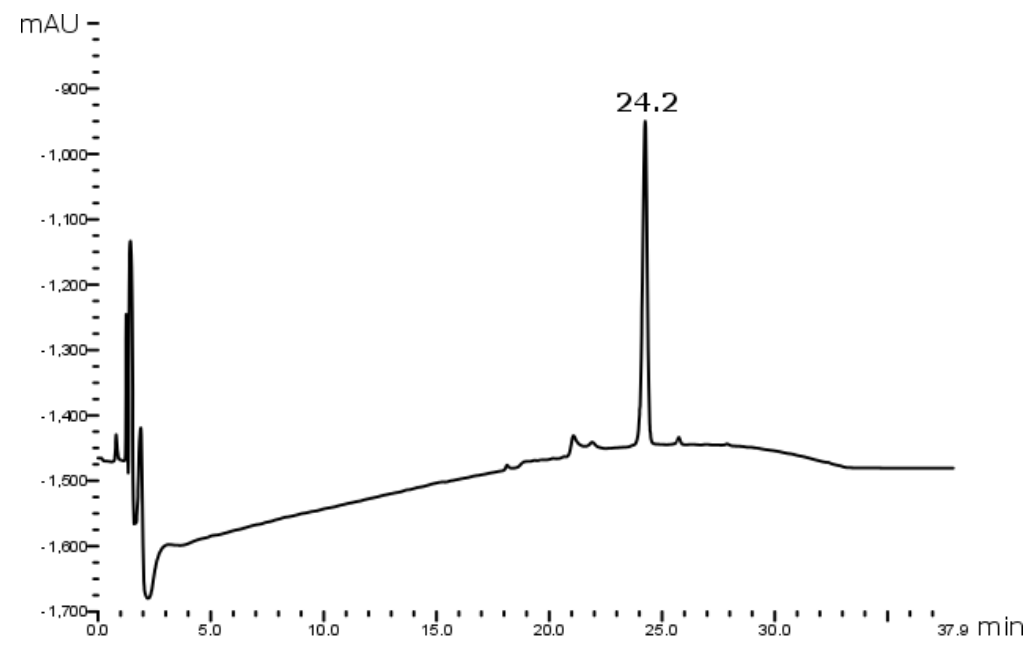

b.

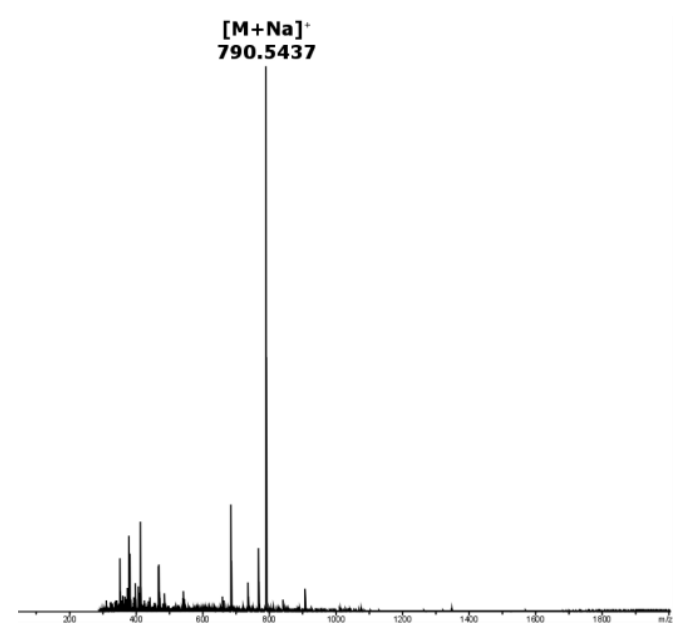

Figure S5. Analytical HPLC chromatogram of purified lipovelutibol D (4), 95\% purity (214 nm, peaks with $t_{R}<4$ min result from solvent spikes during injection); XTerra MS C18, $125 \AA$, $5 \mu \mathrm{m}, 4.6 \times 150 \mathrm{~mm}, 5-95 \% \mathrm{~B}$ at $3 \%$ B per min, $\left.1 \mathrm{~mL} \min ^{-1}\right)$ b. HRMS spectrum of lipovelutibol D (4).

a.

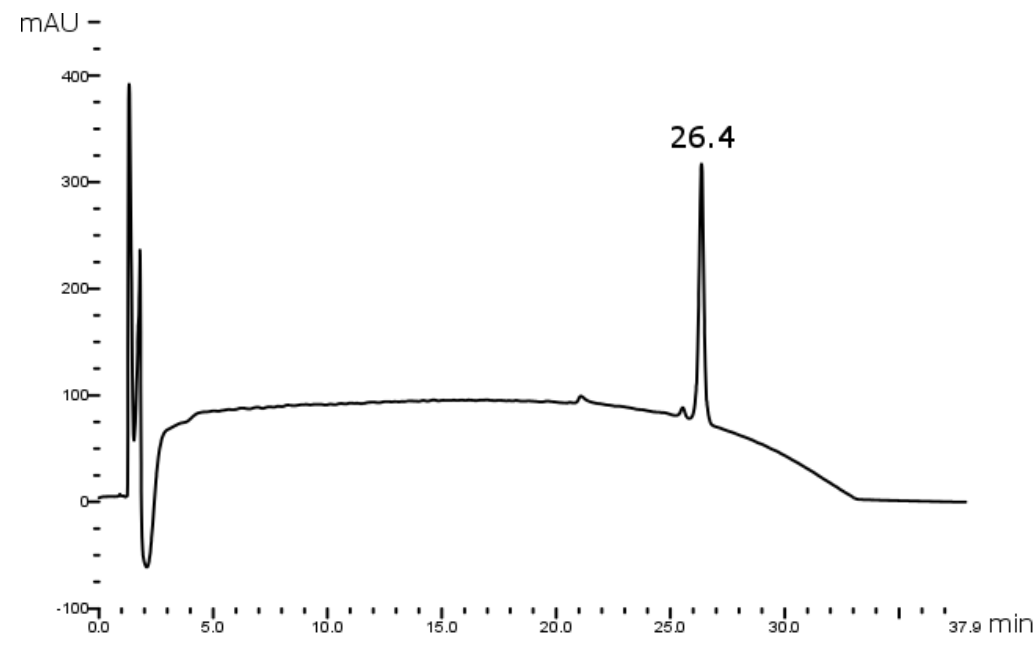

b.

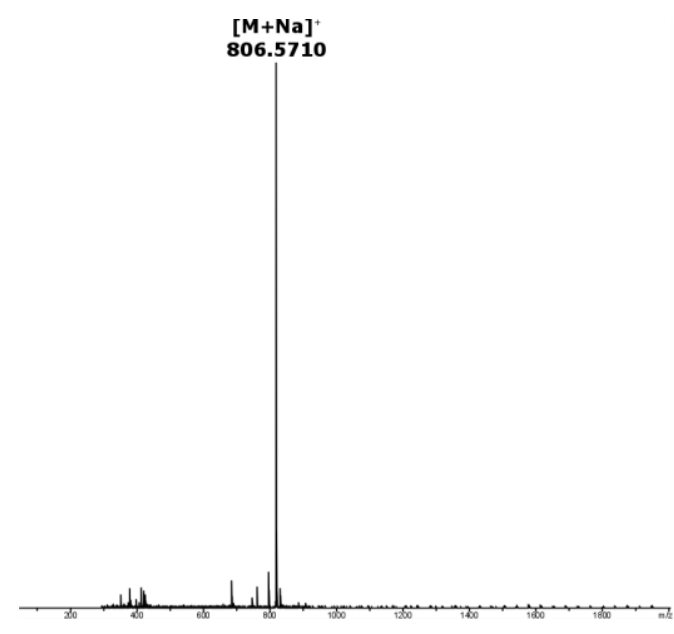

Figure S6. Analytical HPLC chromatogram of purified lipovelutibol D analogue $4 a, 98 \%$ purity ( $214 \mathrm{~nm}$, peaks with $\mathrm{t}_{\mathrm{R}}<4$ min result from solvent spikes during injection); XTerra MS C18, $125 \AA$, $5 \mu \mathrm{m}, 4.6 \times 150 \mathrm{~mm}, 5-95 \% \mathrm{~B}$ at 3\%

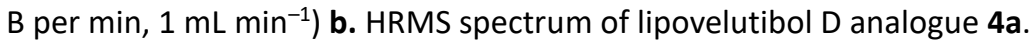


a.

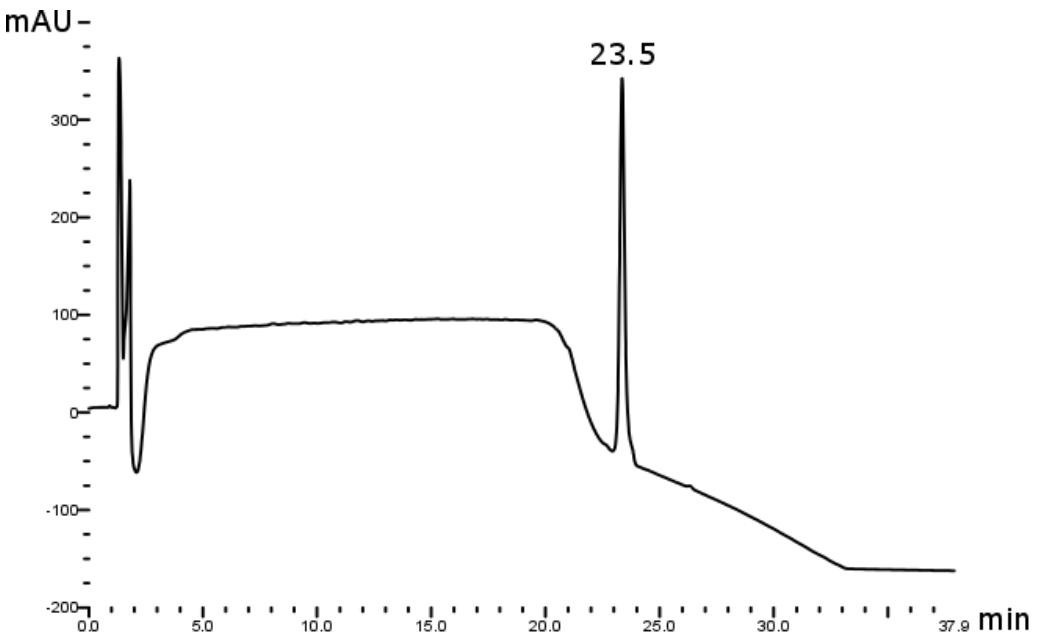

b.

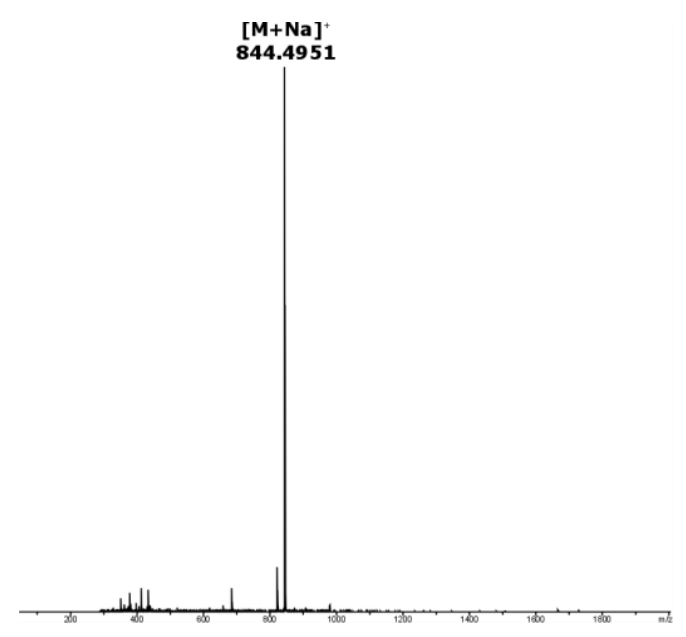

Figure S7. Analytical HPLC chromatogram of purified lipovelutibol D analogue $4 \mathbf{b},>99 \%$ purity (214 nm, peaks with $\mathrm{t}_{\mathrm{R}}<4 \mathrm{~min}$ result from solvent spikes during injection); XTerra MS C18, $125 \AA$, $5 \mu \mathrm{m}, 4.6 \times 150 \mathrm{~mm}, 5-95 \% \mathrm{~B}$ at $3 \%$ B per $\min , 1 \mathrm{~mL} \mathrm{~min}^{-1}$ ) b. HRMS spectrum of lipovelutibol $D$ analogue $\mathbf{4 b}$.

a.

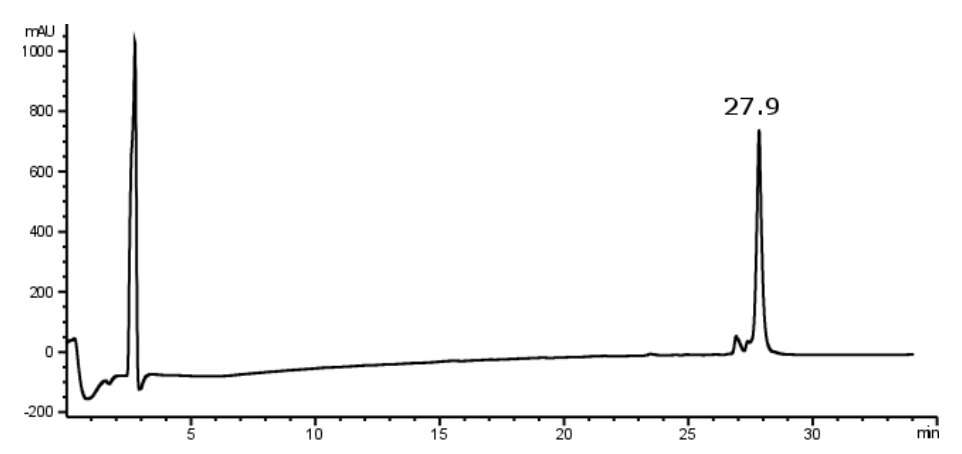

b.

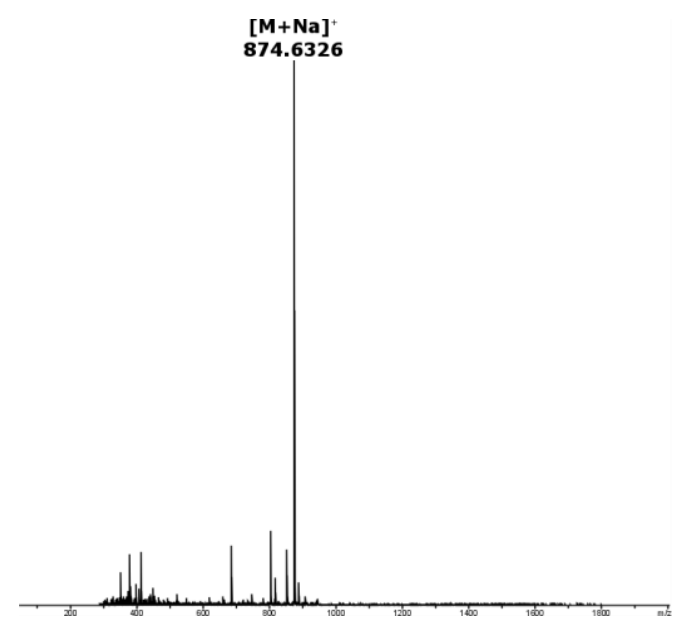

Figure S8. Analytical HPLC chromatogram of purified lipovelutibol D analogue 4c, 95\% purity (214 nm, peaks with $\mathrm{t}_{\mathrm{R}}<4$ min result from solvent spikes during injection); XTerra MS C18, $125 \AA$, $5 \mu \mathrm{m}, 4.6 \times 150 \mathrm{~mm}, 5-95 \% \mathrm{~B}$ at 3\% B per $\left.\min , 1 \mathrm{~mL} \mathrm{~min}{ }^{-1}\right)$ b. HRMS spectrum of lipovelutibol $D$ analogue $4 c$. 


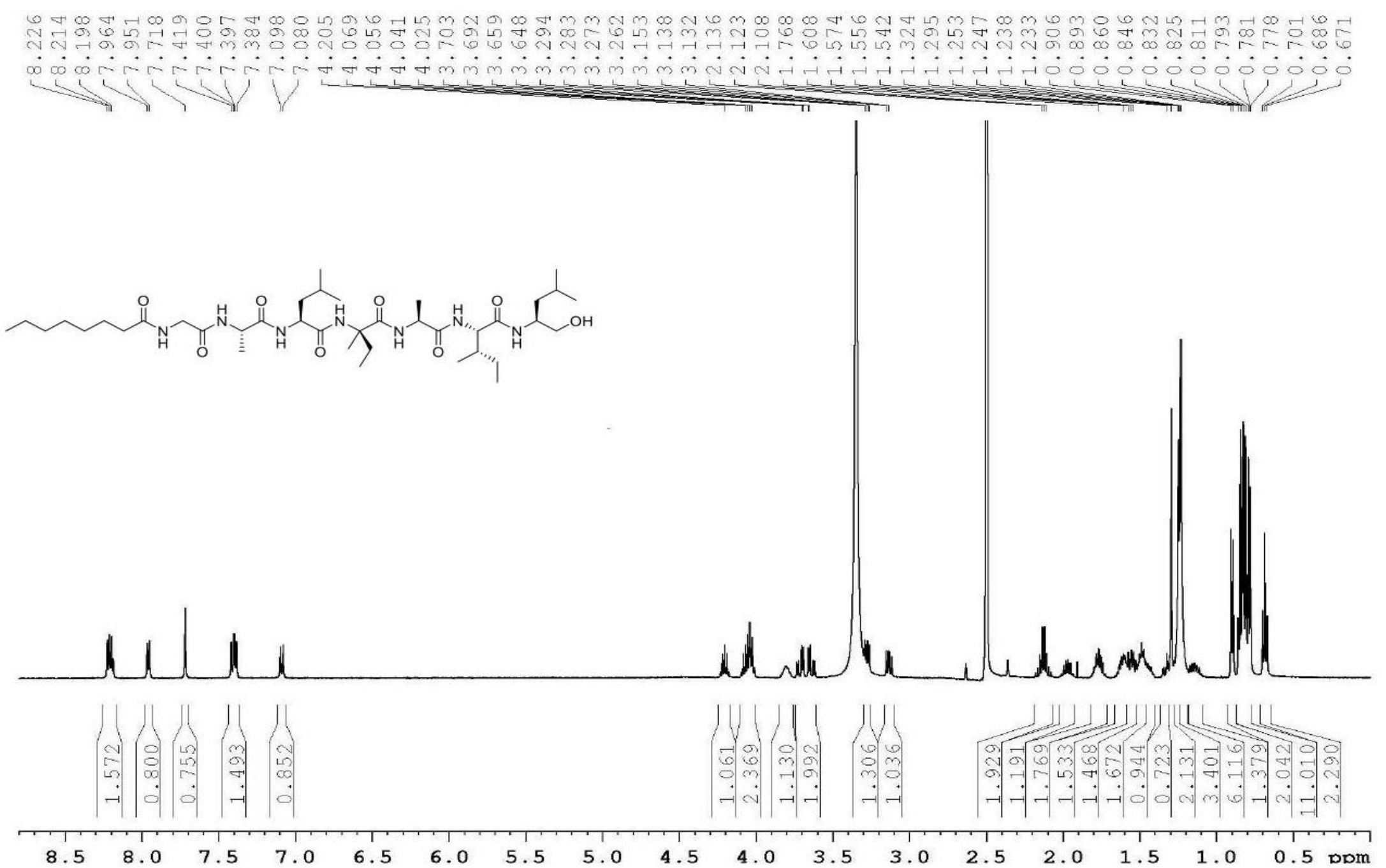

Figure S9. ${ }^{1} \mathrm{H}$ NMR spectrum of lipovelutibol D (4) in DMSO-d $6(500 \mathrm{MHz})$ 


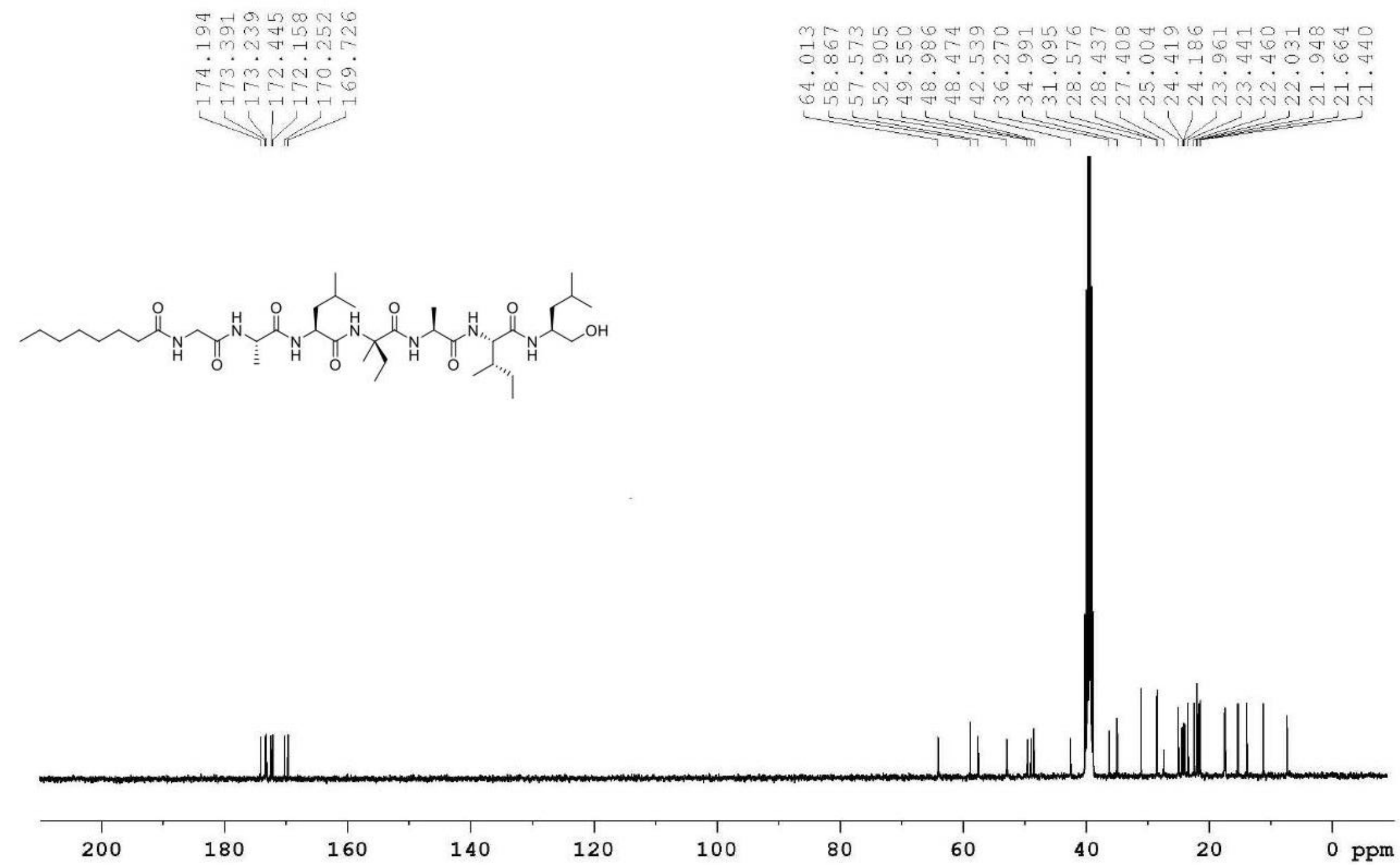

Figure S10. ${ }^{13} \mathrm{C}$ NMR spectrum of lipovelutibol D (4) in DMSO-d 6 (125 MHz) 


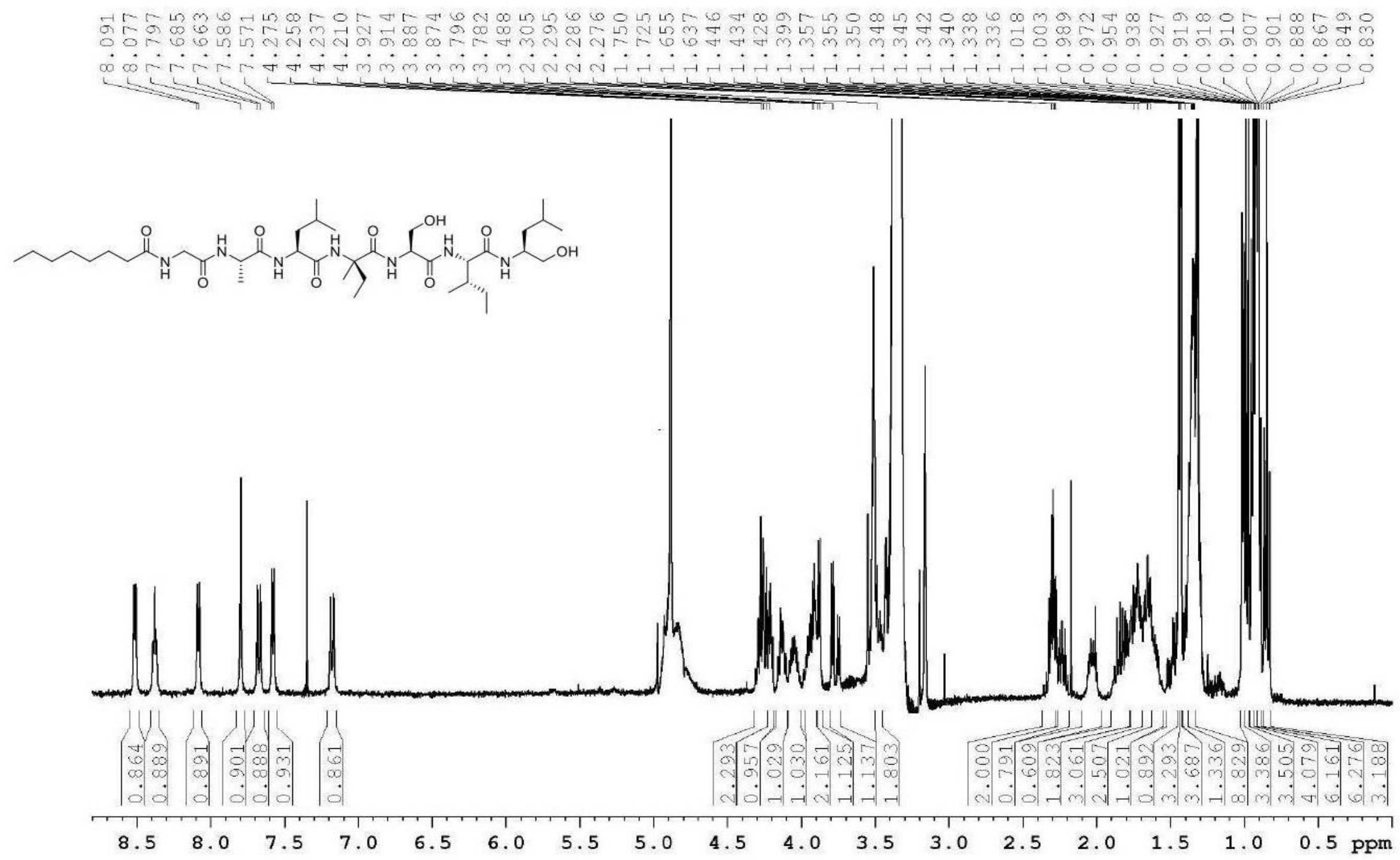

Figure S11. ${ }^{1} \mathrm{H}$ NMR spectrum of lipovelutibol $\mathrm{B}(2)$ in $\mathrm{CD}_{3} \mathrm{OH}(400 \mathrm{MHz})$ 

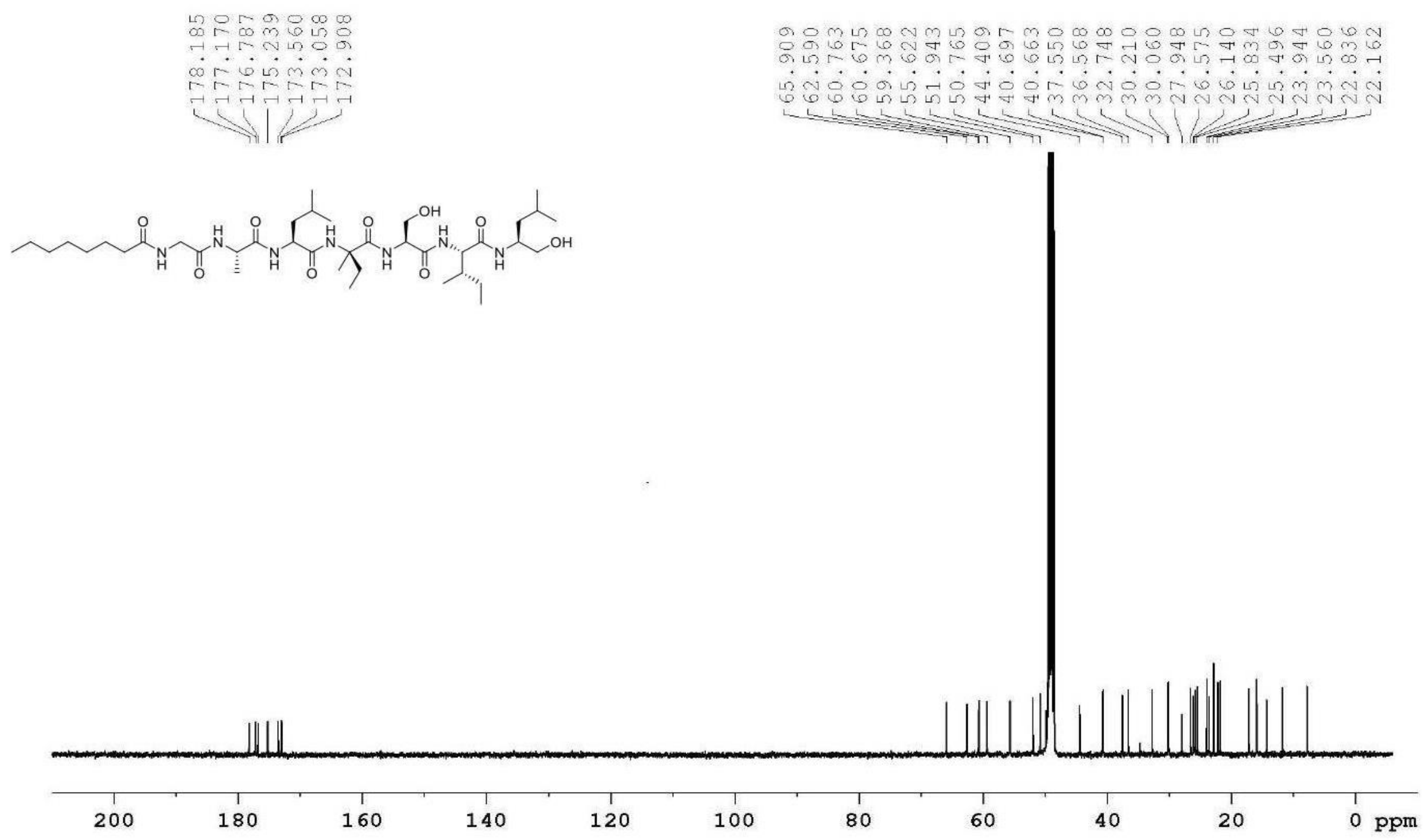

Figure S12. ${ }^{13} \mathrm{C}$ NMR spectrum of lipovelutibol $\mathrm{B}(2)$ in $\mathrm{CD}_{3} \mathrm{OH}(100 \mathrm{MHz})$

S13 
Table S3. MIC $(\mu \mathrm{M})^{\mathrm{a}}$ assay results for fungal and bacterial pathogens.

\begin{tabular}{|c|c|c|c|}
\hline Compound & $\begin{array}{c}\text { P. aeruginosa } \\
\text { (SVB-B9) }\end{array}$ & $\begin{array}{c}\text { S. aureus } \\
\text { (ATCC 29213) }\end{array}$ & $\begin{array}{l}\text { C. utilis } \\
\text { (SVB-Y1) }\end{array}$ \\
\hline 2 & $>128$ & $>128$ & $>128$ \\
\hline $2 a$ & $>128$ & $>128$ & $>128$ \\
\hline $2 b$ & $>128$ & $>128$ & $>128$ \\
\hline $2 c$ & $>128$ & $>128$ & $>128$ \\
\hline 4 & ND & ND & ND \\
\hline $4 a$ & $>128$ & $>128$ & $>128$ \\
\hline $4 b$ & $>128$ & $>128$ & $>128$ \\
\hline $4 c$ & $>128$ & $>128$ & $>128$ \\
\hline polymyxin B & 0.25 & $N D^{b}$ & $N D^{b}$ \\
\hline amoxicillin & $N D^{b}$ & 8 & $N D^{b}$ \\
\hline amphotericin B & $N D^{b}$ & $N D^{b}$ & 2 \\
\hline
\end{tabular}

${ }^{\text {a }}$ MIC defined as lowest concentration with no observable growth at specified time. Concordant results were obtained from three separate experiments with compounds tested in triplicate within each. MIC defined as > $128 \mu \mathrm{M}$ if no inhibitory activity observed within test concentration range.

${ }^{\mathrm{b}} \mathrm{ND}=$ no data 

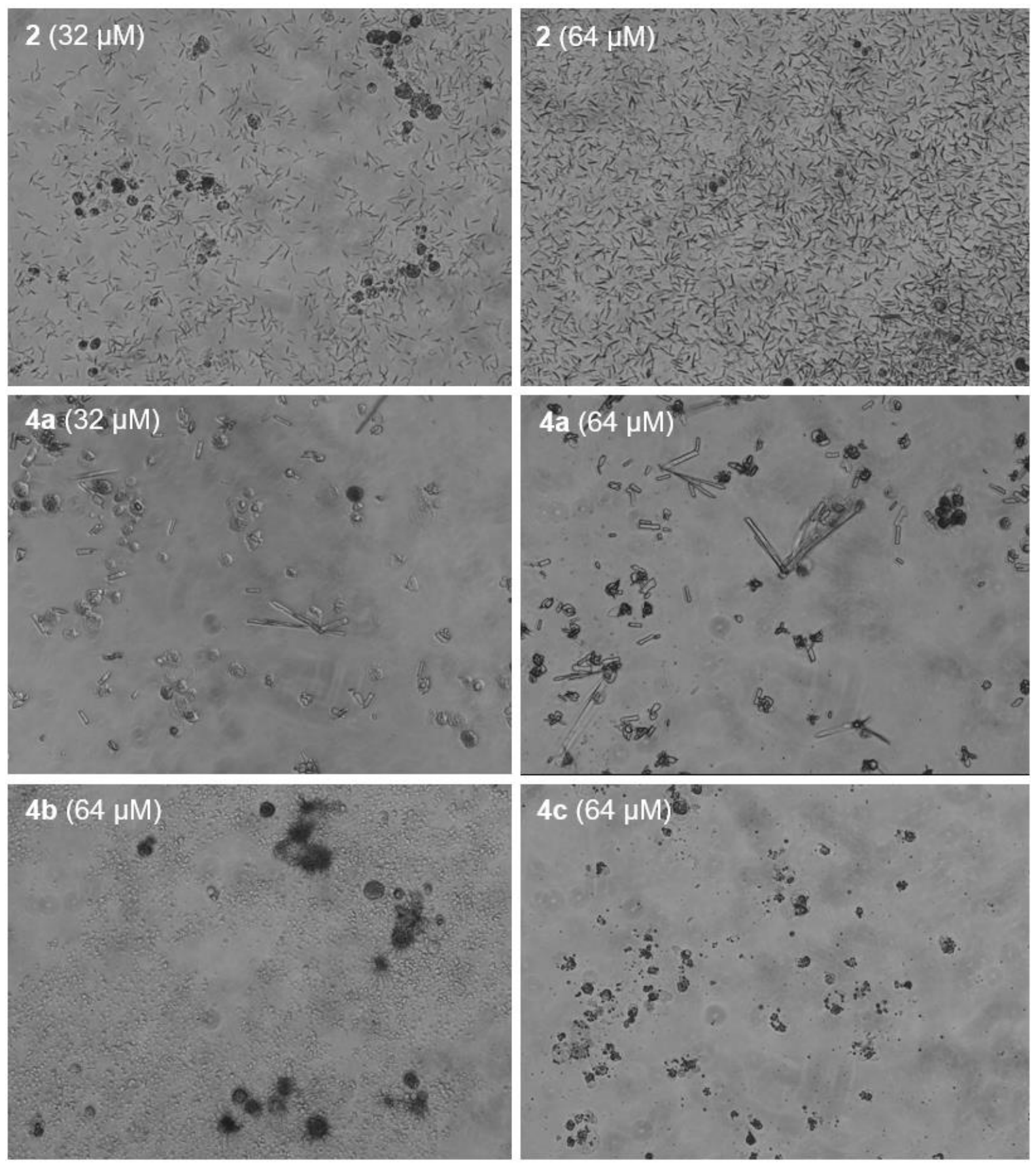

Figure S13. Microscope images (200X magnification) of supramolecular assemblies observed for compound $\mathbf{4}, \mathbf{4 a}$ and $\mathbf{4 b}$ at specified concentrations in media. Compound $\mathbf{4 c}$ is shown at bottom right as an example of the remaining compounds for which no assembly was observed under the microscope. Darkly stained structures represent dead MDA-MB-231 cells. 


\section{References}

(1) Singh, V. P.; Yedukondalu, N.; Sharma, V.; Kushwaha, M.; Sharma, R.; Chaubey, A.; Kumar, A.; Singh, D.; Vishwakarma, R. A. Lipovelutibols A-D: Cytotoxic Lipopeptaibols from the Himalayan Cold Habitat Fungus Trichoderma velutinum. J. Nat. Prod., 2018, 81, 219-226 